\title{
Addendum: Anderson, M., et al. Grassland Management Affects Vegetation Structure, Bats and Their Beetle Prey. Diversity 2020, 12, 406
}

\author{
Max Anderson ${ }^{1}\left(\mathbb{D}\right.$, Lisa Norton ${ }^{2}$ and Fiona Mathews ${ }^{1, *(D)}$ \\ 1 School of Life Sciences, University of Sussex, Falmer, Brighton BN1 9QG, UK; max.anderson@sussex.ac.uk \\ 2 UK Centre of Ecology and Hydrology, Lancaster Environment Centre, Bailrigg, Lancaster LA1 4AP, UK; \\ lrn@ceh.ac.uk \\ * Correspondence: f.mathews@sussex.ac.uk
}

check for updates

Citation: Anderson, M.; Norton, L.; Mathews, F. Addendum: Anderson, M., et al. Grassland Management Affects Vegetation Structure, Bats and Their Beetle Prey. Diversity 2020, 12, 406. Diversity 2021, 13, 16. https://doi.org/10.3390/d13010016

Received: 15 December 2020 Accepted: 15 December 2020 Published: 6 January 2021

Publisher's Note: MDPI stays neutral with regard to jurisdictional clai$\mathrm{ms}$ in published maps and institutional affiliations.

Copyright: (C) 2021 by the authors. Licensee MDPI, Basel, Switzerland. This article is an open access article distributed under the terms and conditions of the Creative Commons Attribution (CC BY) license (https:// creativecommons.org/licenses/by/ $4.0 /)$.

\section{Text Correction}

There was an error in the original article. There was an inadvertent omission of a data availability statement. A correction has been made to include the 'Data Availability Statement' section, immediately following the conclusion.

Data Availability Statement: All of the supporting data used in this study are available through the Figshare digital repository (10.6084/m9.figshare.13302353).

The authors apologize for any inconvenience caused and state that the scientific conclusions are unaffected. The original article has been updated.

\section{Reference}

1. Anderson, M.; Norton, L.; Mathews, F. Grassland Management Affects Vegetation Structure, Bats and Their Beetle Prey. Diversity 2020, 12, 406. [CrossRef] 